\title{
An Experimental Study on the Reinforcement of Silt with Permeable Polyurethane by Penetration Grouting
}

\author{
Chaojie Wang $\mathbb{D}^{1,2}$ Qi Liu $\mathbb{D D}^{1,2}$ Chengchao Guo $\mathbb{D}^{2,3,4}$ Yangyang Xia $\mathbb{D}^{1,{ }^{1,2}}$ Yanjie Hao $\mathbb{D}^{1,2}$ \\ Mingsheng Shi $\mathbb{D}^{1,2}$ and Peng Zhao ${ }^{10}{ }^{1,2}$ \\ ${ }^{1}$ School of Water Science and Engineering, Zhengzhou University, Zhengzhou 450000, China \\ ${ }^{2}$ National and Local Joint Engineering Laboratory for Major Infrastructure Inspection and Repair Technology (Henan), \\ Zhengzhou, China \\ ${ }^{3}$ School of Civil Engineering, Sun Yat-sen University, Guangzhou 510275, China \\ ${ }^{4}$ Guangdong Key Laboratory of Marine Civil Engineering (Guangzhou), Guangzhou 510275, China \\ Correspondence should be addressed to Chengchao Guo; guochch25@mail.sysu.edu.cn
}

Received 5 July 2020; Revised 5 November 2020; Accepted 16 November 2020; Published 28 November 2020

Academic Editor: Xinyu Ye

Copyright ( 2020 Chaojie Wang et al. This is an open access article distributed under the Creative Commons Attribution License, which permits unrestricted use, distribution, and reproduction in any medium, provided the original work is properly cited.

\begin{abstract}
To meet the demand of antiseepage and reinforcement of soil dams, a kind of permeable polyurethane grouting material was developed. A visual steady-pressure grouting test device was designed to study the law of polyurethane diffusion and reinforcement in silt under different pressure, and the interaction mechanism of grout and soil body structure was explored microscopically. The results showed that, with the increase in the grouting pressure, the diffusion speed rose, and the diffusion pattern of grout in the soil also changed from permeation diffusion to permeation splitting. Under the effect of grouting pressure, more tiny cracks will occur in the soil structure, leading to the use of more grout, thus increasing the strength of the consolidated soil by more than 10 times. The results of SEM-EDS and mercury intrusion test proved that the polyurethane had a significant filling effect on the soil structure, which could effectively reduce the porosity of the soil and cement the soil particles through wrapping, complexing, and hydrogen bonding, thereby improving the soil properties. Moreover, the results revealed from a microscopic perspective that the grouting altered the pore structure of the soil structure through the seepage-erosion-splitting coupling effect, but when the grouting pressure exceeded $0.4 \mathrm{MPa}$, the soil particle and grout would be partially remixed and arranged closely, showing a phenomenon of jet grouting. Finally, the material was used in engineering practice, achieving a satisfactory grouting treatment effect.
\end{abstract}

\section{Introduction}

Dams are an important component in the field of flood control and disaster reduction. However, dams have a long history and they have been raised and thickened over many years, so there are shortcomings such as insufficient building quality, many hidden diseases, and complex geological conditions. Seepage and leakage will occur easily in the unfavorable geological sections of dams such as the unbonded soil under the effect of water, and they will further develop into subsidence and landslide [1] and collapse if not promptly repaired. The traditional antiseepage and reinforcement methods of dams include concrete cutoff walls
$[2,3]$, cement-soil mixing piles [4], and high-pressure jet grouting [5]. However, these methods require a long construction period, with a low construction efficiency and greater disturbance to the dam. Therefore, grouting to fill the soil pores and cement the soil is a more effective antiseepage and reinforcement method of dams, and the choice of grouting materials is the key to repair effect.

Cement-based grout is the most commonly used grouting material, and many scholars have studied its performance and diffusion law in the rock soil, yielding impressive results [6-9]. However, most of the existing achievements lie in the water plugging reinforcement of sands and rocks; there are few studies on the grouting 
diffusion law and reinforcement effect in silt and clay, mainly because of the granularity of cement-based grout and the relatively dense soil [10]. Such properties lead to the seepage effect of cement materials during grouting [11-13] and uneven retention and congestion in porous media, making it difficult to keep continuous permeation and diffusion, thus affecting the grouting reinforcement effect. Therefore, the grouting diffusion law of cement in the soil is mainly permeation-compaction-splitting. As a result, more materials are needed for repair and reinforcement in the construction. Moreover, it usually takes some time to maintain the cement-based materials, which also limits their further application [14].

In recent years, due to such characteristics as high permeability and strong cementing power, chemical grouting materials, such as sodium silicate [15], polyurethane [10], butyl acrylate and styrene [16], silica sol [10], lignin sulfonate [17], and polyacrylamide [18, 19], have been applied through permeation grouting in the impermeable reinforcement of the sand. At the same time, electroosmosis [20] and microbial grouting [21] have also gradually become emerging soil reinforcement techniques. The chemical grouting materials generally cement the soil particles via electrostatic and chemical bonding. Meanwhile, they fill the pores of the cluster structure of soil particles [16] and form a thin-film-like structure around the cluster body, thereby improving the stability and strength of the soil body or isolating the contact between soil particles and water to enhance hydrolysis resistance [22]. Despite many achievements about the changes in mechanical properties of special soil bodies such as sandy soils or expansive soils, collapsible soils, and marine clays before and after grouting, the laws of diffusion and performance changes of grout in silt under the influence of grouting pressure have been less studied. In particular, the performance characteristics of soil particle structure under different grouting pressure remain unclear yet under the macro- and microscale conditions.

Due to characteristics such as low viscosity, low density, short gelation time, and high strength and strong chemical stability after solidification [23], polyurethane materials have been widely used in the grouting repair of highways [24, 25], dams [26], tunnels [27], and other infrastructures. However, the main material used is polyurethane, which is able to quickly react and expand. As a result, it is difficult to permeate into the soil pores and can only diffuse in the soil in the form of splitting [26].

Therefore, based on the concept of "permeable cementing," a new type of permeable polyurethane grouting material was developed in this paper, which was characterized by low viscosity, high permeability, and strong cementing power. A laboratory steady-pressure grouting device was designed to simulate the soil permeation grouting process, and the diffusion law of permeable polyurethane grouting material in silt and its influence law on soil mechanical properties under different grouting pressure were studied. Moreover, the changes in micropore structure of consolidated body were revealed through scanning electron microscope-energy dispersive spectroscopy (SEM-EDS) and mercury intrusion test, and the microscopic mechanism of grouting pressure on the soil particle structure was proposed. Finally, the material was applied to engineering practice to verify its reinforcement and filling effect on the soil.

\section{Materials and Test Methods}

2.1. Grouting Test System. To study the law of effect of grout on silt under different grouting pressure, according to the design thought of grouting model test in the literature $[10,28]$, an indoor visual steady-pressure grouting simulation test device was developed. The schematic diagram and the real product are shown in Figures 1 and 2, respectively. The device mainly contains a double-liquid grouting system, a grouting mold, and a test rack. The double-liquid grouting system is characterized by fine proportioning, controllable pressure, and atomization mixing, which can ensure the continuous injection of grout under constant pressure. The two lifting pumps of the grouting system can extract components A and B of polymer separately and mix them at the grouting gun (reaction frame). Then the grouting gun is connected to the grouting pipe through the grouting cap to inject the mixture into the soil body. The grouting pressure can be adjusted between 0 and $7 \mathrm{MPa}$, and continuous steady-pressure grouting can be realized. The grouting mold is composed of an acrylic tube (inner diameter: $150 \mathrm{~mm}$, height: $300 \mathrm{~mm}$, and thickness: $10 \mathrm{~mm}$ ), a grouting cap, an exhaust valve, screws, nuts and sealing rubber pads used for fixation and sealing, and upper and lower bases, and there is a pressure gauge at the grouting cap, which can record the pressure in the internal mold during the grouting process in real time.

2.2. Test Methods. The specific test methods include the following steps:

(1) First, a layer of butter (about $1 \mathrm{~mm}$ thick) was evenly smeared inside the acrylic tube and the inner sides of the upper and lower bases for demolding.

(2) A layer of filter screen and sealing rubber pads were laid on the lower base of the mold, and the acrylic tube was placed on the slot of the lower base. The soil mass required for each test was calculated according to the porosity required. Then the soil was equally divided into 3 parts, which were placed in the mold for 3 times and compacted layer by layer.

(3) The sealing rubber pad was placed inside the base of mold, and then the mold was assembled and tightened using bolts.

(4) The soil was inserted into the grouting pipe which was inserted into the soil body at a depth of $10 \mathrm{~cm}$ through drilling using the grouting cap.

(5) The exhaust valve of the lower base was opened, and then grouting began. The diffusion and pressure changes in the mold were monitored using a highdefinition camera. To compare the diffusion position, the mold was divided into 5 parts longitudinally $(10 \mathrm{~cm}, 15 \mathrm{~cm}, 20 \mathrm{~cm}, 25 \mathrm{~cm}$, and $30 \mathrm{~cm})$ according to 


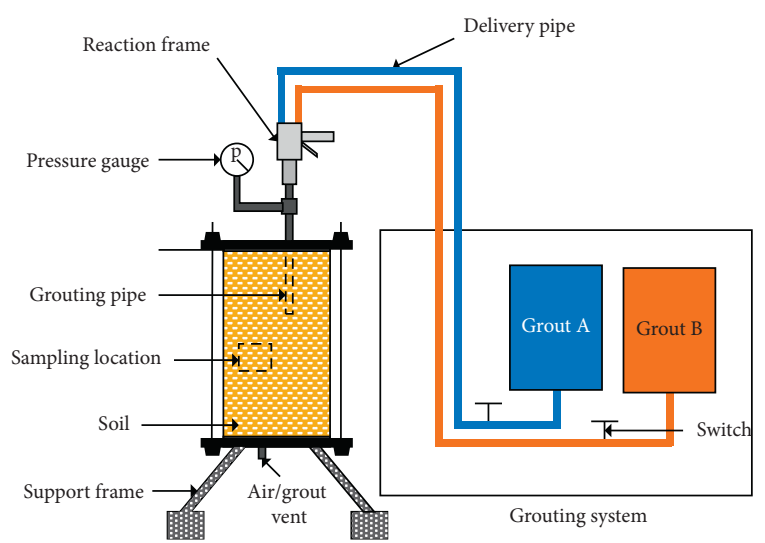

Figure 1: Schematic diagram of grouting device.

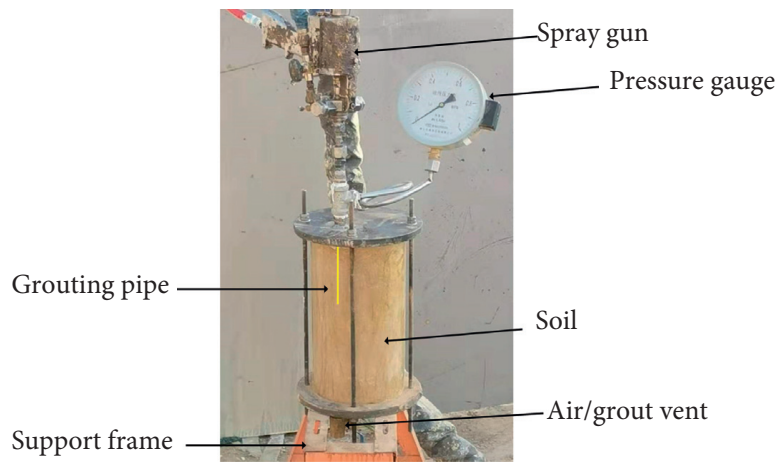

Figure 2: Picture of the experimental setup.

the distance from the grouting port, and the diffusion law of grout in the soil body was explored through comparing the time of grout diffusion to different parts.

(6) The exhaust valve was closed after the discharge of grout from the exhaust valve at the base, the grout diffusion and pressure changes in the sleeve were observed, and grouting was stopped when the designed grouting volume was reached. The grouting volume, soil porosity, and density were $3.12 \mathrm{~kg}, 49 \%$, and $1.5 \mathrm{~g} / \mathrm{cm}^{3}$, respectively.

(7) The mold was removed at $1 \mathrm{~d}$ after grouting, and the treated soil in the mold was maintained at room temperature. After $3 \mathrm{~d}$, the grouting specimens were sampled using a dicing saw and a clay cutter, and then the unconfined compressive strength was measured using a TCK-1 triaxial test controller. The soil samples were taken after unconfined compressive strength test. After metal spraying, microstructure test was performed using a Quanta FEG 250 high-resolution field emission scanning electron microscope, the element distribution in the specimen was analyzed using X-ray EDS, and the pore structure of samples was tested using AutoPore IV 9500 mercury injection apparatus after unconfined compressive strength test.
2.3. Test Materials. The test soil was taken from a construction site in Zhengzhou, Henan Province, China. The basic physical properties of soil obtained from the basic soil test are shown in Table 1, and the particle grading curve is shown in Figure 3. It can be seen from Table 1 and Figure 3 that the particle size of the test soil was mainly $0.025-0.075 \mathrm{~mm}$, and the proportion of particle size less than $0.075 \mathrm{~mm}$ was $87.32 \%$. Therefore, it can be determined that the soil is low liquid limit silt according to "Test Methods of Soils for Highway Engineering” (JTG E40-2007).

The grouting material used in the test was permeable polyurethane, and components $\mathrm{A}$ and $\mathrm{B}$ were produced by reaction at a 1:1 mass ratio. Component $\mathrm{A}$ was mainly composed of hydrophilic low-viscosity polyether polyol, permeable diluent, and surfactant, and component B was mainly composed of isocyanate. Its main performance is shown in Table 2.

The time-varying curve of the viscosity of polyurethane obtained using the VISCOQC viscometer is shown in Figure 4 . It can be seen that the initial viscosity of the polymer was relatively lower, about $5.3 \mathrm{mPa} \cdot \mathrm{s}$, close to the viscosity of water. Therefore, the polyurethane has good permeability and can penetrate into the tiny pores of the soil. At the same time, the viscosity of the polyurethane changes slowly with time and has mutability. The permeable polymer can keep a low-viscosity state of less than $10 \mathrm{mPa} \cdot \mathrm{s}$ in the first $1000 \mathrm{~s}$ and begins to solidify at $1000-1500 \mathrm{~s}$, and its viscosity rapidly rises after $1500 \mathrm{~s}$. It can be seen that the permeable polyurethane reacts slowly in the early stage, and its viscosity can remain stable during the reaction and then rapidly rises after the reaction, so the effective grouting time should be controlled within $1500 \mathrm{~s}$. Based on such a property, controlling the grouting pressure can realize fixed-point repair of dams at different depths.

\section{Analysis of Polyurethane Diffusion Law}

3.1. Analysis of Polyurethane Diffusion Distance. The diffusion of grout in the soil under different grouting pressure is shown in Figures 5(a) and 5(b) which display the relation between time and diffusion distance under different grouting pressure, in which the grouting pressure refers to the continuous pressure provided by the integrated steadypressure grouting system. As shown in Figure 5(a), with the increase in grouting pressure, the time for the grout filling in the mold declined; that is, the overall diffusion rate of grout increased. When the grouting pressure was $0.1 \mathrm{MPa}$, the time for grout filling in the mold was $145 \mathrm{~s}$, mainly because permeation diffusion of grout is dominated under such grouting pressure, leading to a lower diffusion rate. When the grouting pressure increased to $0.2 \mathrm{MPa}$, the grout diffusion rate rose rapidly, and the time for the grout filling in the mold declined to $30 \mathrm{~s}$. At this time, splitting diffusion occurred in the soil body. However, when the grouting pressure continued to rise, it had little impact on the overall grout diffusion rate.

Figure 5(b) displays the grout diffusion speed at different distances. The higher the grouting pressure, the higher the grout diffusion speed at different positions, and the 
TABLE 1: Intrinsic properties of the soil.

\begin{tabular}{|c|c|c|c|c|c|}
\hline Specific gravity $G_{S}$ & $\begin{array}{l}\text { Percent moisture } \\
\text { content of liquid } \\
\text { limit } w_{\mathrm{L}} \%\end{array}$ & $\begin{array}{c}\text { Percent moisture } \\
\text { content of plastic limit } w_{\mathrm{P}} \%\end{array}$ & $\begin{array}{l}\text { Plasticity } \\
\text { index } I_{\mathrm{P}}\end{array}$ & $\begin{array}{l}\text { Natural moisture } \\
\text { content } \%\end{array}$ & $\begin{array}{c}\text { Maximum dry } \\
\text { density } \rho_{\text {dmax }} / \text { g.cm }\end{array}$ \\
\hline 2.70 & 22.90 & 14.70 & 8.20 & 8.70 & 1.72 \\
\hline
\end{tabular}

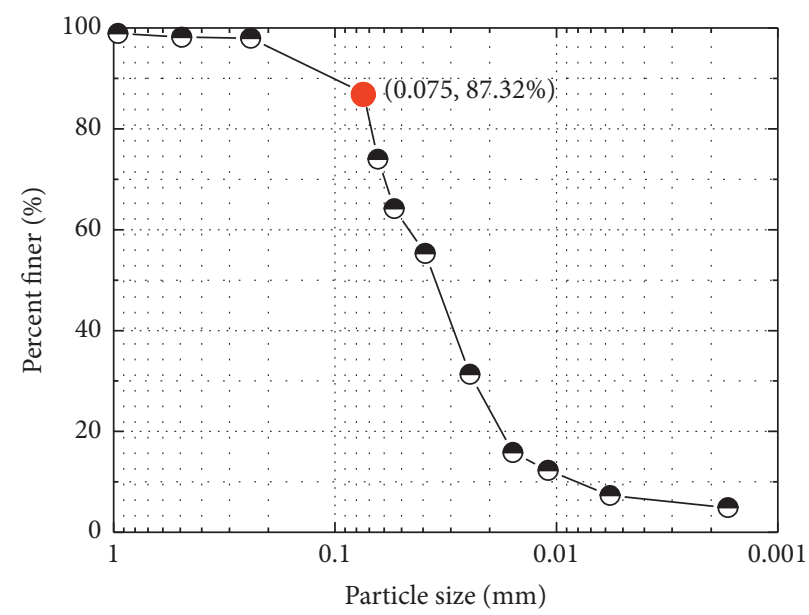

Figure 3: Grain size distribution of soils.

TABle 2: Properties and composition of permeable polyurethane.

\begin{tabular}{lcccc}
\hline The initial viscosity, $\mathrm{mPa} \cdot \mathrm{s}$ & Density, $\mathrm{g} / \mathrm{cm}^{3}$ & Compressive strength, $\mathrm{MPa}$ & Components & Viscosity, $\mathrm{mPa} \cdot \mathrm{s}$ \\
\hline & & & & $\begin{array}{c}\text { Hydrophilic low-viscosity polyether } \\
\text { polyol }\end{array}$ \\
5.3 & 1.2 & 2.3 & A & $\begin{array}{c}\text { Permeable diluent } \\
\text { Surfactant } \\
\end{array}$ \\
& & B & Isocyanate \\
\hline
\end{tabular}

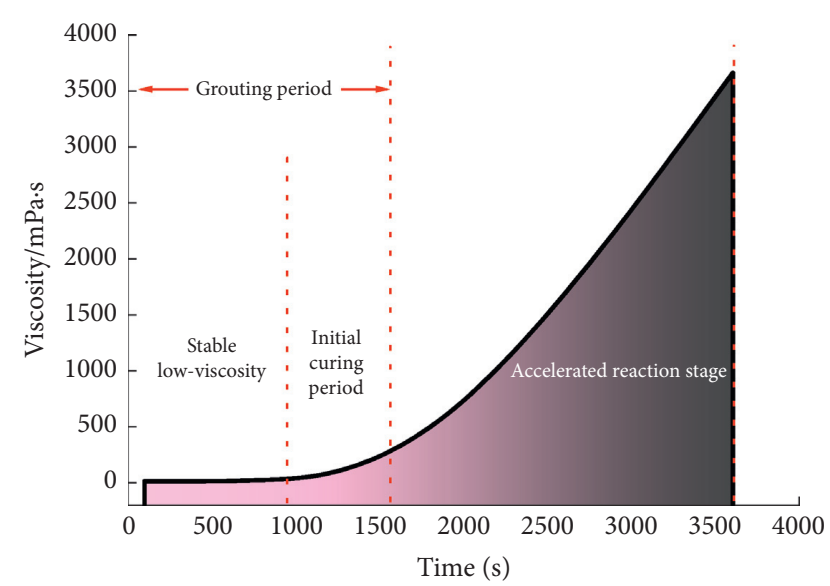

FIgURE 4: Schematic diagrams of viscosity changes with time.

development trend of grout diffusion speed varied under different grouting pressure. When the grouting pressure was $0.1 \mathrm{MPa}$, the grout diffusion speed declined linearly and slowly, as the air pressure in the soil pores gradually accumulates and is not dissipated promptly to lead to a certain resistance. When the grouting pressure was $0.2 \mathrm{MPa}$ and
$0.3 \mathrm{MPa}$, the grout diffusion speed first rose and then declined, mainly because of soil splitting under such grouting pressure. The splitting cracks increase the diffusion speed, and then the grout continues to permeate and diffuse radially along the splitting cracks, thus lowering the speed. When the grouting pressure was $0.4 \mathrm{MPa}$, the grout diffusion rate first rose and then declined and rose again. This is because the grouting pressure of $0.4 \mathrm{MPa}$ is too large, completely splitting the soil body, breaking the contact between soil particles, and leading to the mixing of the particles and grout. As a result, a similar effect to jet grouting is shown during the grouting process, thus increasing the speed again.

3.2. Analysis of Pressure Changes in the Container during Grouting. The pressure changes in the mold during the grouting process are shown in Figure 6. During the grouting process, the pressure changes in the mold have very obvious stage characteristics, including three stages (rapid growth, stable development, and later increase). In the rapid growth stage, the pressure in the mold rose rapidly as the grouting started. The higher grouting pressure corresponded to the higher pressure in the mold and higher increase rate of pressure. In the stable development stage, the grouting 


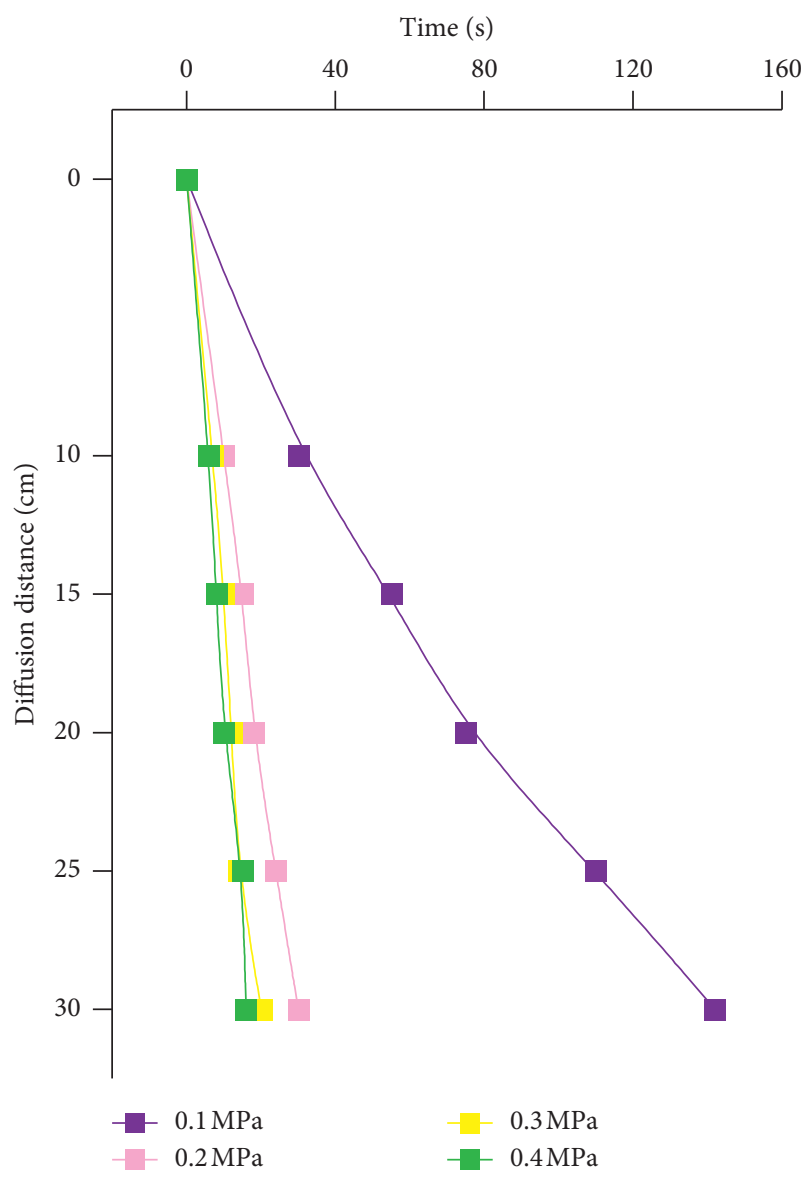

(a)

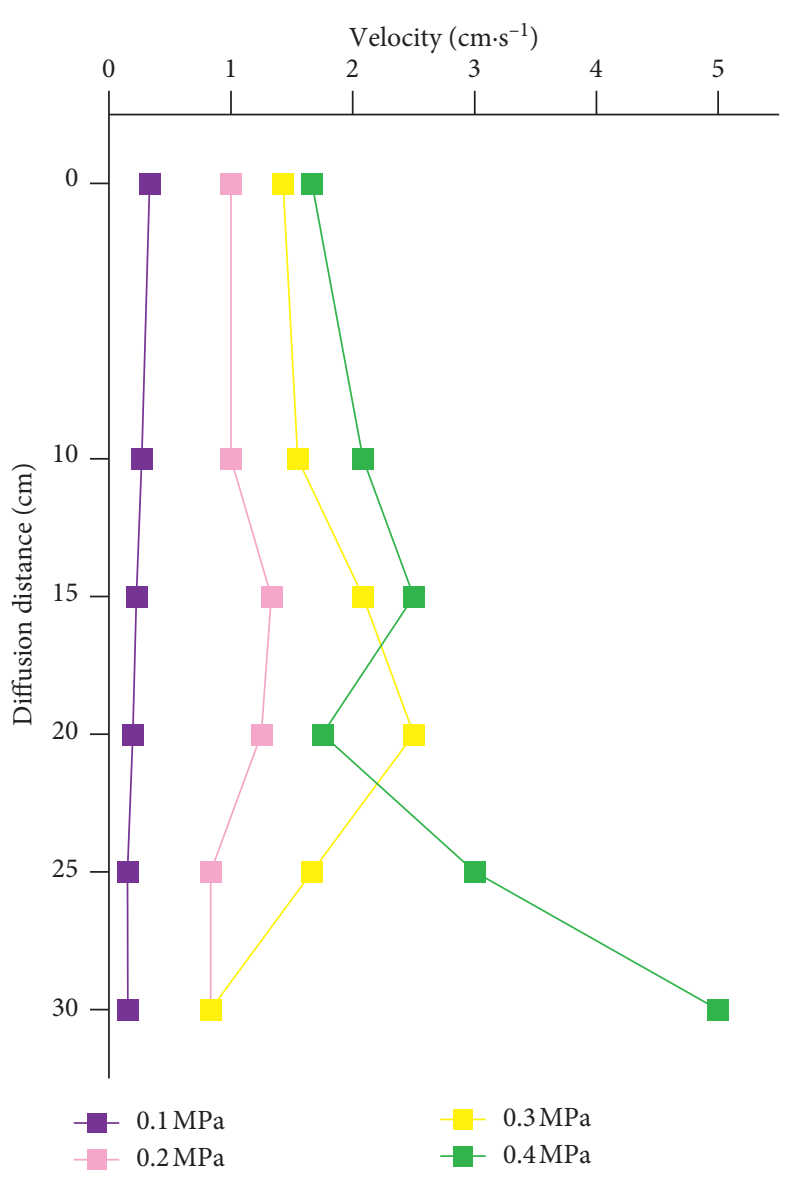

(b)

Figure 5: The law of grouting diffusion in soil. (a) The relationship between time and diffusion distance. (b) The relationship between velocity and diffusion distance.

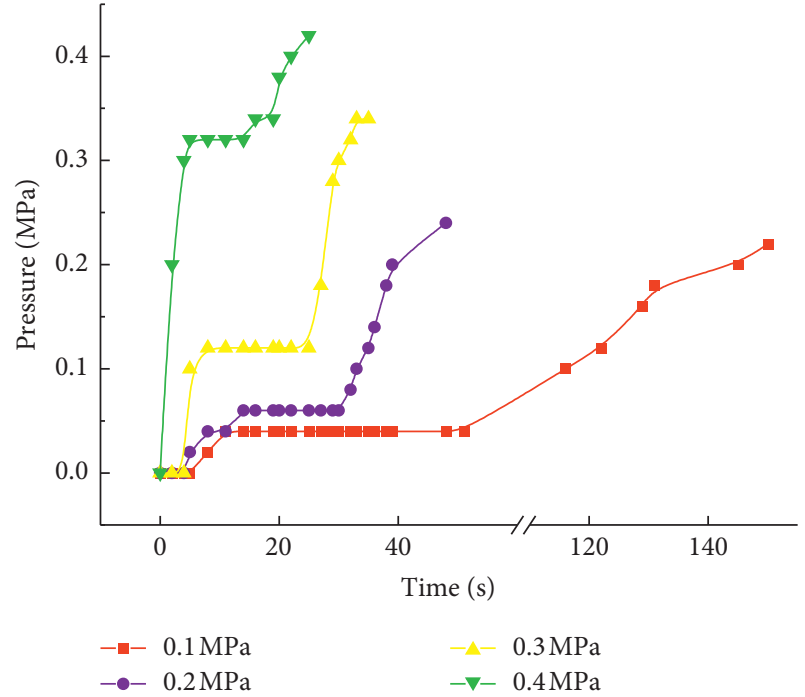

Figure 6: Pressure change in die during grouting.

continued, but the pressure in the mold remained unchanged. This is because the grout gradually permeates and fills the soil pores under small pressure, during which there is no great resistance against grout diffusion. When the grouting pressure is up to $0.2-0.4 \mathrm{MPa}$, decompression occurs due to splitting diffusion; that is why the pressure remains unchanged. In the later stage, the pressure increased, because the grout continues to diffuse but the air in the soil pores is not dissipated promptly. Moreover, when the grouting pressure was $0.2-0.4 \mathrm{MPa}$, grouting still continued till the designed grout volume though the grout had diffused to the bottom of the container, so the pressure continued to rise. The process of changes in the pressure in the mold with time under the grouting pressure of $0.3 \mathrm{MPa}$ is shown in Figure 7.

3.3. Grouting Process Analysis. The grouting process under different grouting pressures is shown in Figure 8. It was found that when the grouting pressure was $0.1 \mathrm{MPa}$, the surface of soil in the mold was intact, indicating that the grout slowly permeates into the pores of the soil body under the pressure, without causing disturbance to the soil structure, so the grout diffusion rate slightly declines with time, but the pressure in the mold can remain unchanged for a longer time. When the grouting pressure rose to $0.2 \mathrm{MPa}$, the grout began to disturb the skeleton structure of the soil, 


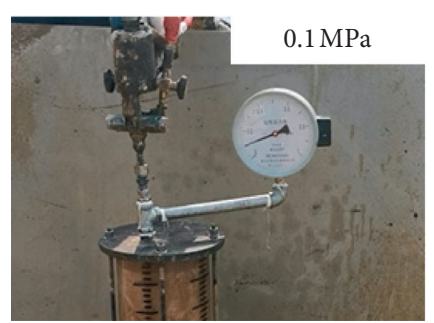

(a)

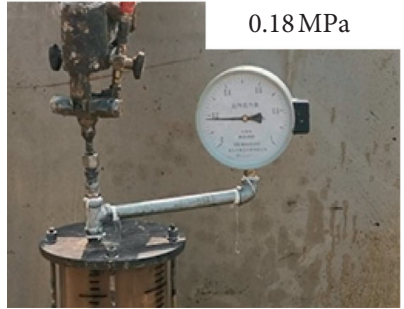

(b)

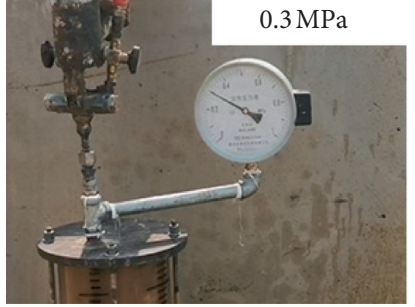

(c)

FIgURE 7: The pressure inside the die changes with time during the grouting under $0.3 \mathrm{MPa}$. (a) $5 \mathrm{~s}$. (b) $10 \mathrm{~s}$. (c) $30 \mathrm{~s}$.
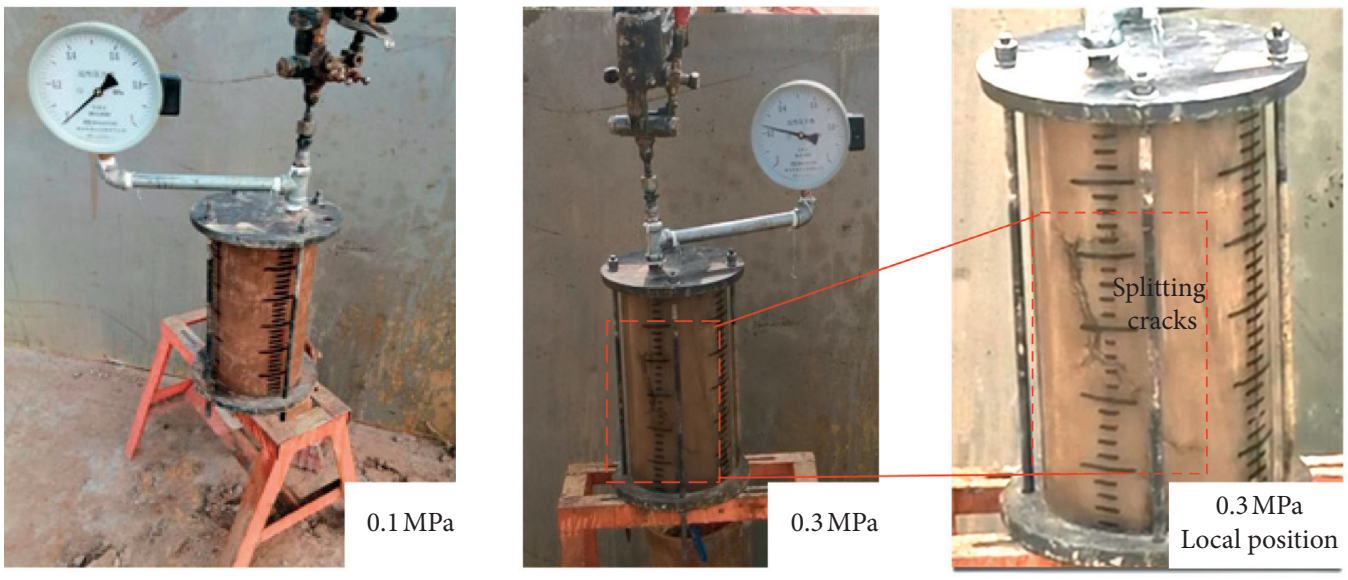

Figure 8: Grouting process under grouting pressures of $0.1 \mathrm{MPa}$ and $0.3 \mathrm{MPa}$.

producing microcracks in the soil gradually. Then the gradual accumulation of microcracks promoted the formation of splitting cracks in the soil macroscopically. Figure 9(a) is a side view of the treated soil under the grouting pressure of $0.2 \mathrm{MPa}$. It is the formation of splitting cracks that promoted the increase in grout diffusion speed at $15 \mathrm{~cm}$, and then the grouting pressure of $0.2 \mathrm{MPa}$ was not enough to produce more microcracks in the soil body, so the grout continued to diffuse in the form of permeation. Therefore, the grout diffusion speed declined at $20-30 \mathrm{~cm}$, and the soil was not completely split. That is why there were no obvious cracks at the bottom of the treated soil, as shown in Figure 9(c). When the grouting pressure was $0.3 \mathrm{MPa}$, more obvious splitting cracks were produced during the grouting process. As shown in Figure 8 (b) and (c), the splitting cracks were produced during the grouting process under the grouting pressure of $0.3 \mathrm{MPa}$ suddenly without warning. The above findings suggest that splitting cracks are produced after the microcracks in the soil body gradually accumulate to a certain extent, and the grout diffusion speed at $15 \mathrm{~cm}$ rises more obviously and the decompression also occurs earlier at this time, indicating that the grouting pressure completely exceeds the splitting pressure of the soil body. Figures 9(b) and 9(d) exhibit the treated soil after grouting under the grouting pressure of $0.3 \mathrm{MPa}$. It can be observed that the specimen had more obvious splitting cracks macroscopically, the grout was filled in the splitting cracks, and splitting cracks also emerged at the bottom of the specimen. However, despite splitting diffusion of grout, the soil body was still cemented into a whole, suggesting that the grout still permeates into the pores of the remaining soil in the form of permeation diffusion after splitting. When the grouting pressure continued to increase to $0.4 \mathrm{MPa}$, the phenomenon of high-pressure jet grouting occurred. The skeleton structure of soil around the splitting cracks was broken up, and the soil particles were mixed with the grout while splitting cracks were produced in the soil body, so its diffusion speed further rose after decline, and the stable stage of the pressure in the mold also lasted for a shorter time.

Therefore, it is concluded that the macroscopic diffusion modes of polyurethane in the soil body include permeation diffusion and splitting diffusion. Permeation diffusion exists throughout the entire grouting process. Splitting diffusion is produced after the microcracks in the soil body accumulate to a certain extent under the pressure. However, when the grouting pressure is further increased, the phenomenon of jet grouting will locally occur.

\section{Analysis on Consolidation Mechanism of Silty Soil}

4.1. Analysis of Unconfined Compressive Strength. Unconfined compressive strength reflects the maximum bearing capacity of the treated soil samples, which is an important index for evaluating the grouting effect. The changes in strength of the samples with the grouting 


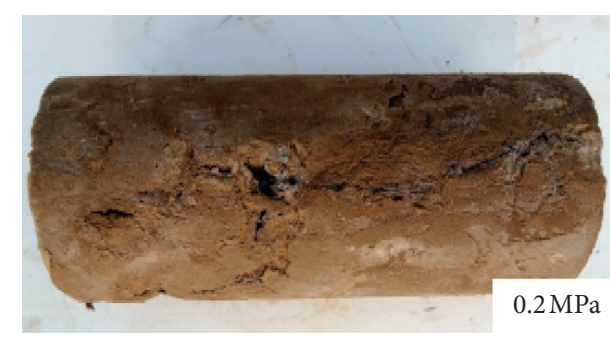

(a)

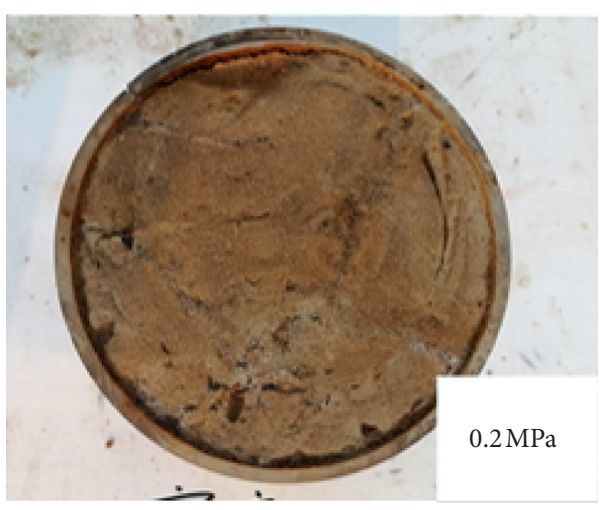

(c)

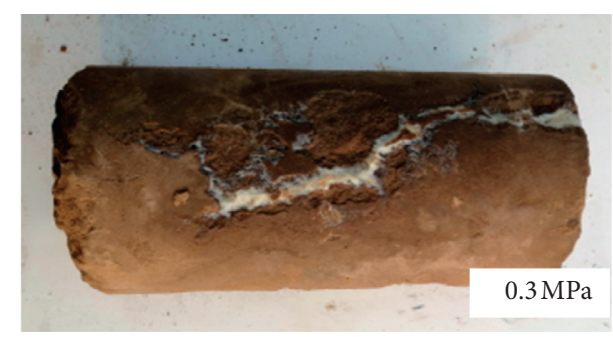

(b)

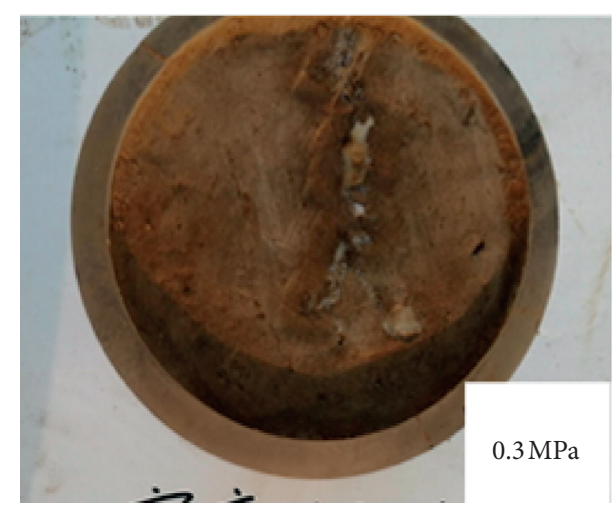

(d)

FIgURE 9: Soil consolidation morphology under different grouting pressure. (a) Profile 0.2 MPa. (b) Profile 0.3 MPa. (c) Bottom 0.2 MPa. (d) Bottom 0.3 MPa.

pressure are shown in Figure 10. It can be seen that the improvement effect of grouting on the soil strength was obvious, and the grouting pressure had a linear relation with the strength of the samples; that is, the higher the grouting pressure, the higher the strength of the treated soil. For example, the compressive strength of the soil sample before grouting was $0.28 \mathrm{MPa}$, and the strength of the treated soil rose to $1.69 \mathrm{MPa}$ under the grouting pressure of $0.1 \mathrm{MPa}$. In spite of splitting diffusion under the grouting pressure of $0.3 \mathrm{MPa}$, the strength could also be increased to $3.19 \mathrm{MPa}$. It is indicated that the permeable polyurethane has an excellent reinforcement effect on the silt, and it can permeate and fill the soil pores and then cement the loose soil particles into one, thereby obviously improving the strength of the soil body. At the same time, the increase of grouting pressure leads to the increase of microcracks in the soil body, and the grout continuously fills the microcracks, so the content of polyurethane grout in the consolidated body continuously rises, thus cementing more soil bodies and further improving the degree of strength. Therefore, the higher the grouting pressure, the higher the strength of the treated soil. The strength rose to $4.34 \mathrm{MPa}$ under the grouting pressure of $0.4 \mathrm{MPa}$, which was believed to be due to the mixing effect of soil particles and grout similar to that of jet grouting, so the strength increased more significantly.

4.2. Micromorphology Analysis. In essence, the changes in the macrophysical and mechanical properties of soil body are caused by the differences in internal materials and structures. Therefore, it is necessary to study the influence of the grout on the structure of the soil body from a

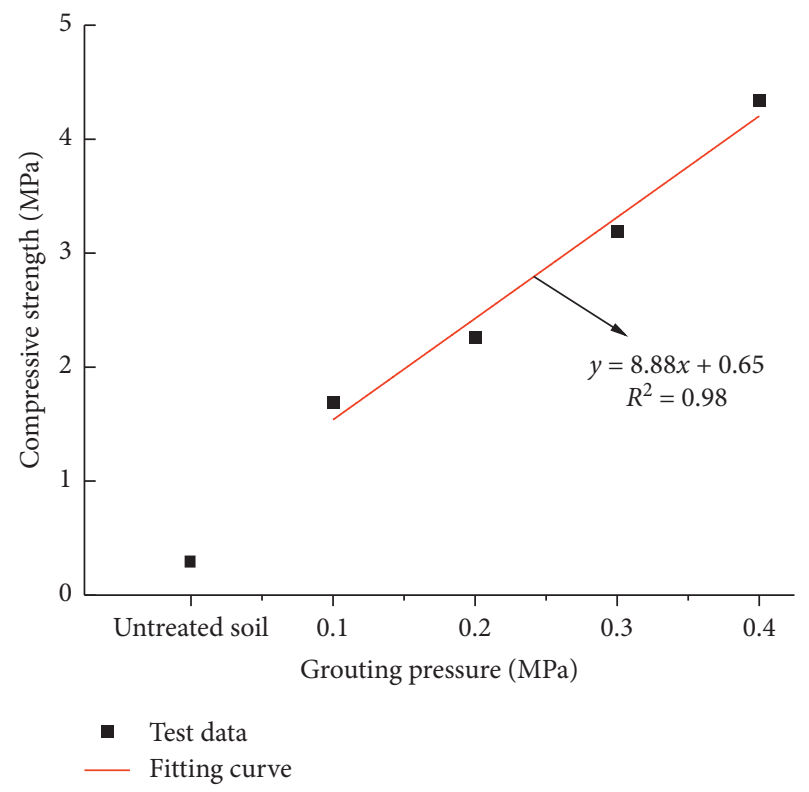

FIgURE 10: Variation of compressive strength with grouting pressure.

microscopic perspective. The micromorphology of the samples observed by a scanning electron microscope is shown in Figure 11. It can be seen from Figure 11(a) that, before the grouting, the soil body has a loose granular aerial structure with many pores. According to Figures 11(b)11(e), the grout penetrates into the soil body after grouting and fills in the pores, reducing the porosity. Meanwhile, polyurethane has a cementing effect, which can enhance the 


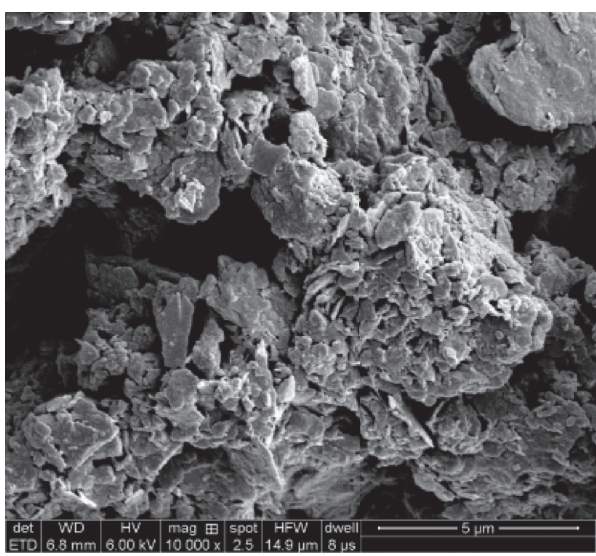

(a)

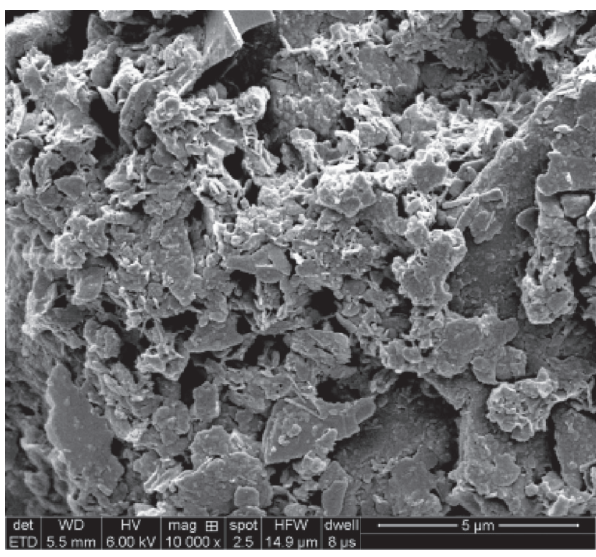

(c)

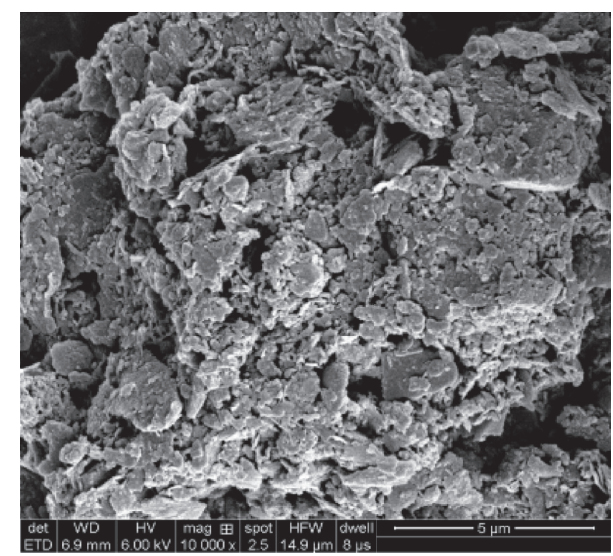

(b)

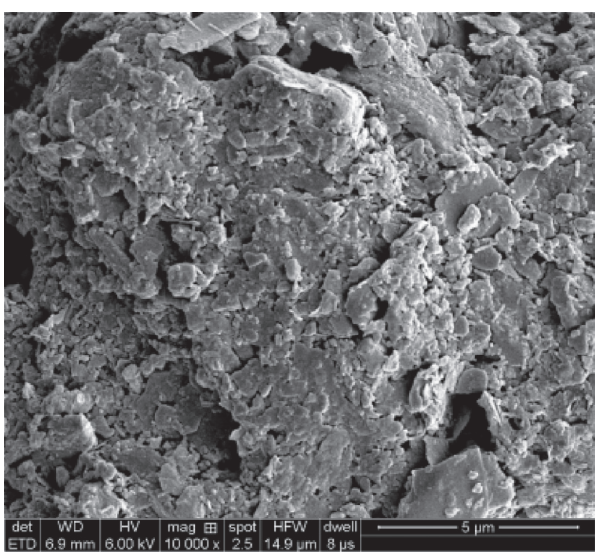

(d)

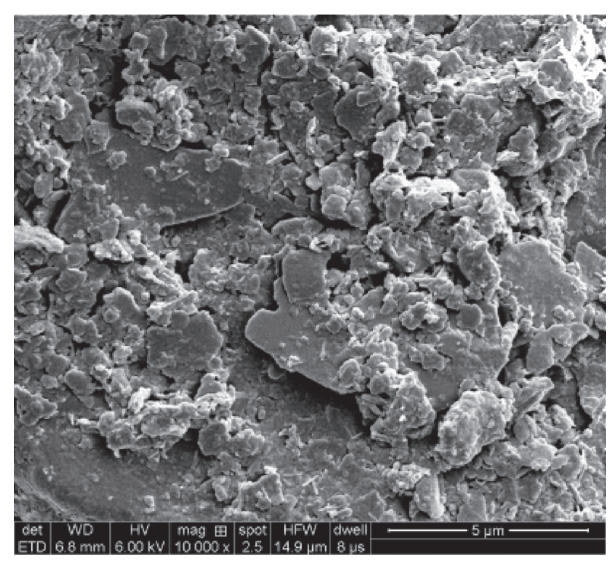

(e)

Figure 11: SEM results of bare soil and improved soil. (a) Untreated. (b) $0.1 \mathrm{MPa}$. (c) $0.2 \mathrm{MPa}$. (d) $0.3 \mathrm{MPa}$. (e) $0.4 \mathrm{MPa}$.

bonding force between the soil particles and cement loose soil particles to form cluster structures. Then the cluster structures can be firmly connected to improve its strength. With the increase of grouting pressure, such an improvement effect becomes more obvious.

EDS can be used to observe the types of elements and their content in the microarea. Therefore, the consolidation mechanism of permeable polyurethane was speculated using EDS, so as to provide a theoretical basis for the application of polyurethane grouting in engineering practice. The polyurethane is an organic macromolecule polymer composed of four elements $(\mathrm{C}, \mathrm{O}, \mathrm{H}$, and $\mathrm{N})$, and the major elements are $\mathrm{C}$ and $\mathrm{O}$ according to EDS. As shown in Table 3, after the chemical reaction of the grout, the content of element $\mathrm{C}$, derived from polyurethane, on the surface of the soil body was increased, indicating that the polyurethane can adhere to and permeate into the surface of soil particles and cement the soil body. Moreover, the soil particles adhere to each other via polyurethane. In addition, the above conclusion was also confirmed by the relation curve between the 
TABLe 3: Sample element composition.

\begin{tabular}{lcccccc}
\hline \multirow{2}{*}{ Element } & & \multicolumn{4}{c}{ Quality percentage } \\
& Untreated soil & $0.1 \mathrm{MPa}$ & $0.2 \mathrm{MPa}$ & $0.3 \mathrm{MPa}$ & $0.4 \mathrm{MPa}$ & Polyurethane \\
\hline $\mathrm{C}$ & 12.67 & 27.72 & 31.64 & 36.82 & 38.79 & 71.58 \\
$\mathrm{O}$ & 46.74 & 42.96 & 42.37 & 41.17 & 38.23 & 28.42 \\
$\mathrm{Si}$ & 12.04 & 7.72 & 8.74 & 6.38 & 7.75 & \\
\hline
\end{tabular}

unconfined compressive strength and the content of element $\mathrm{C}$ in Figure 12, further suggesting that the increase of element $\mathrm{C}$ means that the increase of polyurethane content can effectively improve the strength of the soil. At the same time, the decline in silicon element indicates that the hydroxyl and carboxyl groups in the polyurethane can undergo complexation with the silicon ion of the soil particles, based on which molecular bonds can cement different soil particles to form a solid network. Besides, the oxygen content did not rise but slightly declined; its possible reason is that the carboxyl group in the polyurethane and the hydroxyl silicate on the surface of the soil are deoxidized to form hydrogen bonds. The hydrogen bonds have more stable structure, so the consolidated body has higher structural strength.

4.3. Pore Structure Analysis. Pore size distribution is an important parameter reflecting the pore structure of porous media, while mercury injection apparatus can display the distribution characteristics of pore size more objectively. The pore size of the soil is the only factor without direct relation with the chemical properties among those affecting its physical and mechanical properties, and the changes in the pore structure can basically reflect the reinforcement effect on the soil intuitively. It can be seen from Figure 13 that the soil had a unimodal pore structure before grouting, and the pore size was mainly $10000 \mathrm{~nm}$. However, the pore structure was altered greatly after grouting, mainly around $1000 \mathrm{~nm}$, and the microbimodal pore structure was shown, indicating that the grout fills the pores to increase the micropores and small pores in the soil body. Therefore, the overall performance was obvious movement towards small pores, and the higher the pressure, the more obvious the filling effect. Under the grouting pressure of $0.4 \mathrm{MPa}$, the skeleton structure of the soil body was disturbed, and the soil particles and grout were remixed and arranged closely, so the microbimodal structure disappeared. In Figure 14, it was found that the pore volume of the sample significantly declined after grouting, and the porosity and median pore size also greatly declined, confirming a significant filling effect of polyurethane, also consistent with the SEM results.

4.4. Analysis of Micromechanism of Grouting. The mechanism of grouting alters the pore structure of the soil body, so completely different properties are exhibited. In [5], the micromechanism of jet grouting on the soil body with different pore structures (coarse-grained soil, silt, low-water clay, and saturated clay) includes 4 types: seepage, erosion, erosion splitting, and splitting. However, the above classification is based on jet grouting, and the mechanism of

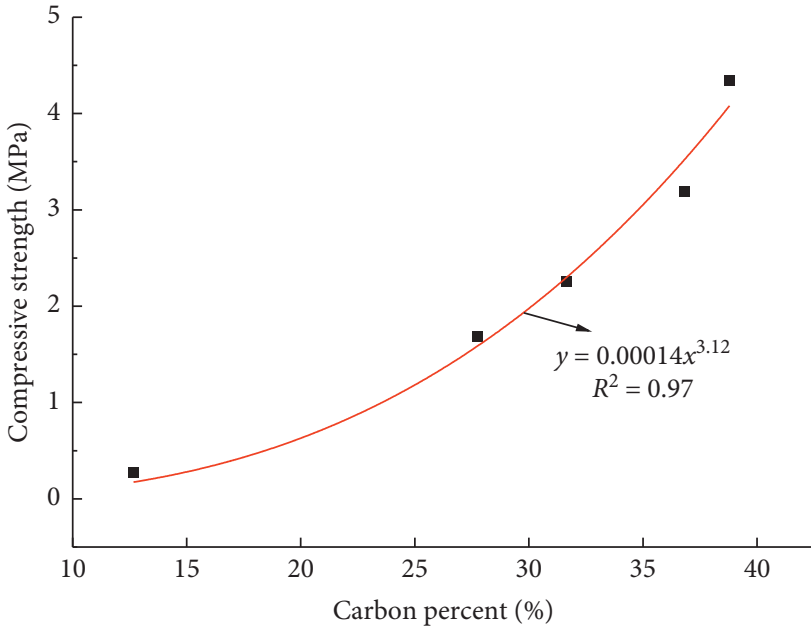

- Test data

- Fitting curve

FIgURE 12: Relationship between carbon content and compressive strength.

action on the soil body will not change significantly under high pressure even if the grouting pressure is altered. In the case of low-pressure permeation grouting, however, according to the performance of the same type of soil under different grouting pressure, it can also be classified into 4 types. For example, the diffusion process of polyurethane in the silt can also be divided into 4 types. The micromechanism of grouting on the soil body is shown in Figure 15. According to its performance under different grouting pressure, it can be classified into 4 types: seepage, erosion, erosion splitting, and complete splitting. (1) Seepage: At this time, the grout permeates into the pores of the soil body under small grouting pressure, and the skeleton structure of the soil particles is not altered. (2) Erosion: After the grouting pressure is increased, the grout permeates into the pores and begins to impact the soil skeleton, causing disturbance to the original soil and making soil particles separate from the original area. As a result, microcracks are produced, and the grout occupies the newly formed cracks and wraps the separated soil particles, forming a cluster structure. (3) Erosion splitting: As the grouting pressure continues to rise, the disturbance effect of the grout on the soil structure becomes greater, producing more pores and cracks in the original soil body. The grout will also capture more separated soil particles, forming a larger cluster structure. At this time, the pores and cracks will gradually accumulate, showing more obvious splitting cracks macroscopically. (4) Complete splitting: The grouting pressure 


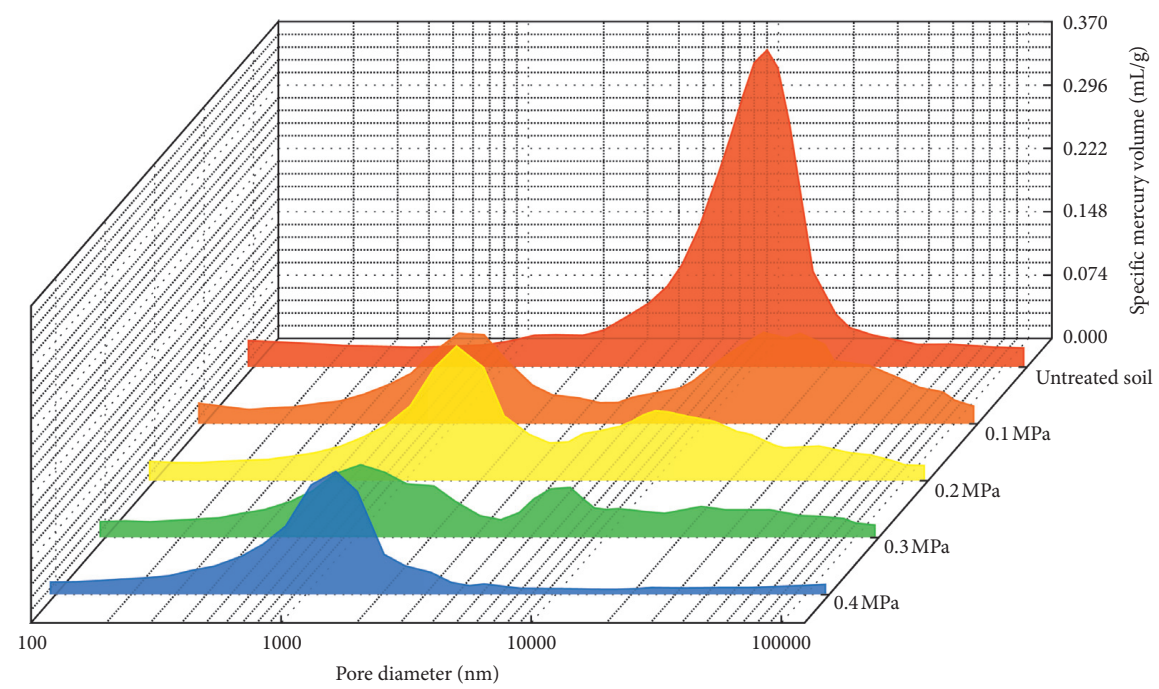

Figure 13: Influence of grouting on aperture distribution.

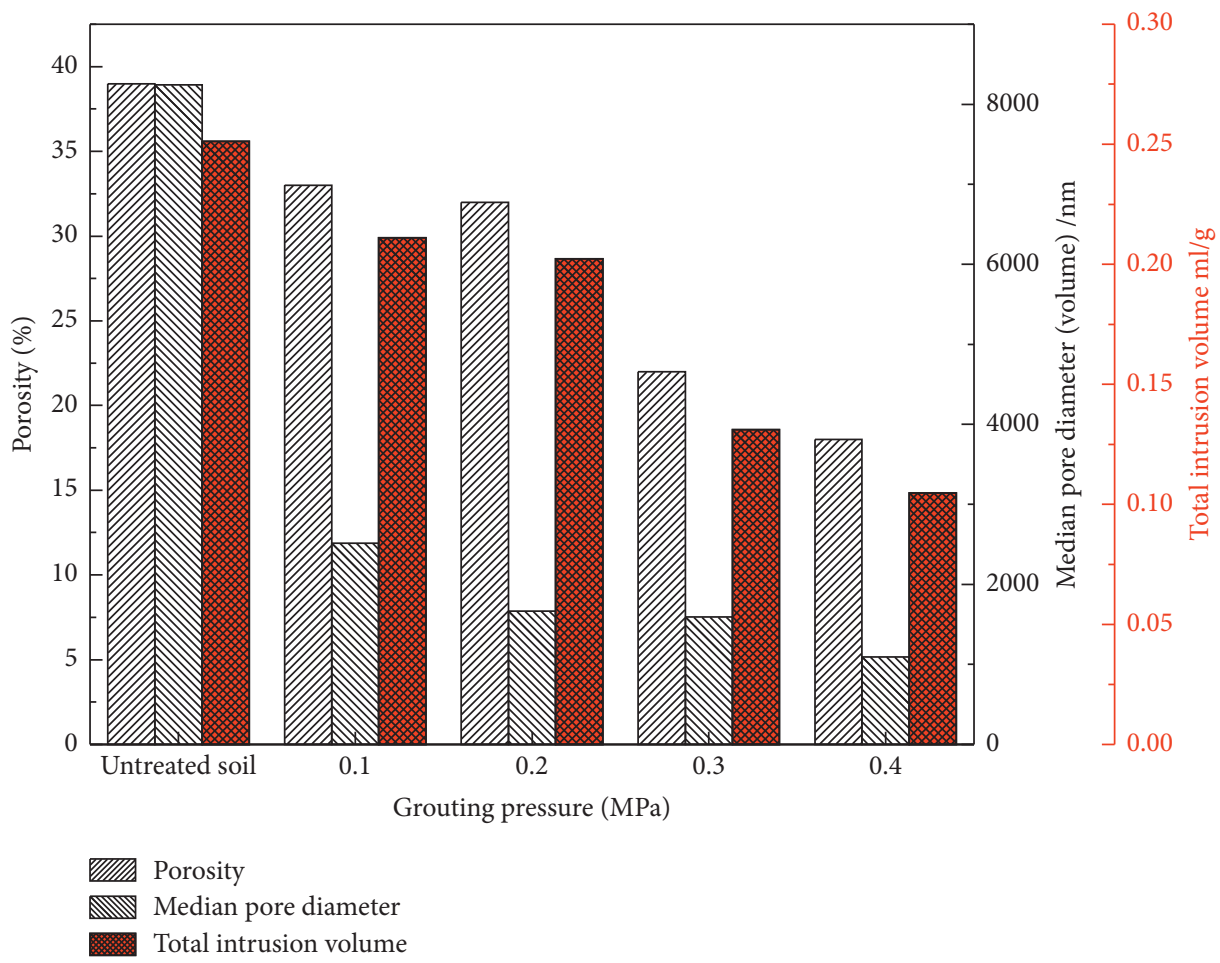

FIGURE 14: Influence of grouting on characteristic values of pore structure.

continues to increase, and a large number of soil particles separate from the surface of the soil body, forming splitting cracks. Then the grout and separated soil particles are fully mixed and arranged locally along the splitting cracks, leading to a tightly packed state and showing a similar effect to jet grouting. Therefore, different grouting pressure for the same type of soil will show different properties. For example, seepage type is usually found in coarse-grained soil, while complete splitting usually occurs in mucky clay.

It was found from the test results and the micromechanism of the grout that it is the grouting pressure that made changes in the pore structure of particles, and the macroscopic behaviors of the treated soil varied under different pressure. The grout diffusion process was the seepage type under the grouting pressure of $0.1 \mathrm{MPa}$, the erosion type under the pressure of $0.2 \mathrm{MPa}$, the erosion splitting type under the pressure of $0.3 \mathrm{MPa}$, and the complete splitting type under the pressure of $0.4 \mathrm{MPa}$. The mechanism of grouting was confirmed by the treated specimen morphology, strength increase curve, and pore size distribution results, and it is the combined action of seepage-erosion-splitting that changed the pore structure 


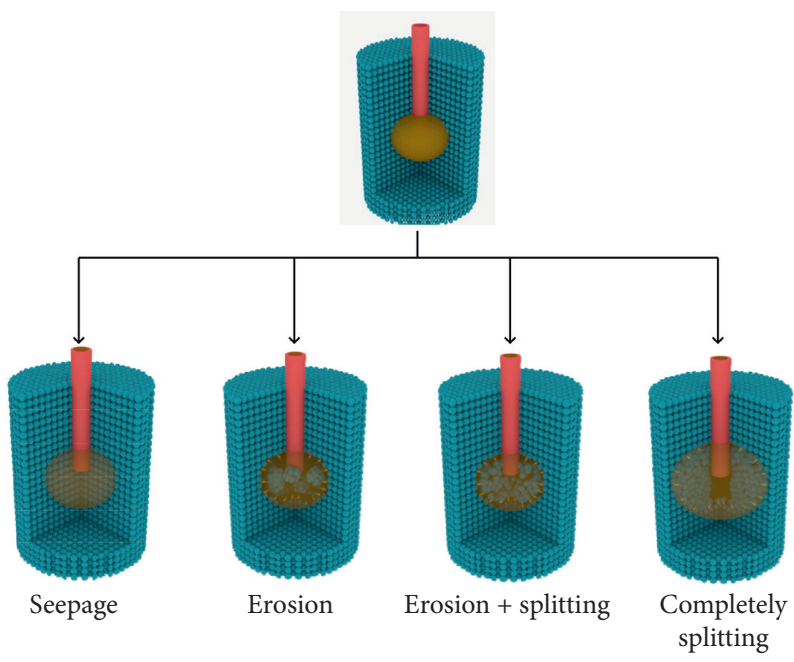

Figure 15: Mechanisms of interaction between grouting and soil (the red round pipe represents the grouting pipe; blue spheres represent soil particles; yellow arrows indicate that grout impinges on soil particles under grouting pressure).

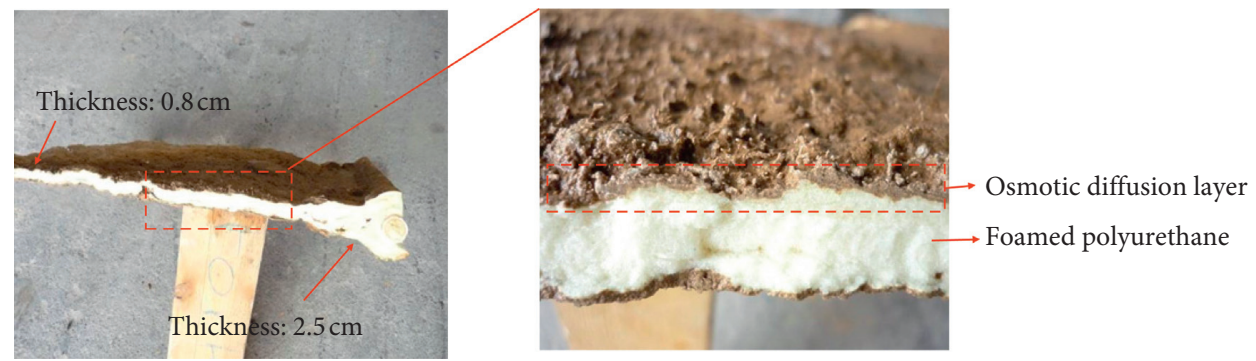

FiguRE 16: Split diffusion pattern of foaming polyurethane [26].

of the soil body. In the seepage type, due to the air resistance in the pores, the grout did not completely fill all the pores, so the pore size distribution still exhibited a bimodal structure under the grouting pressure of $0.1 \mathrm{MPa}$. After the grouting pressure was increased, the grout filled more pores to disturb the soil body, so that more soil particles separated from the original soil body, producing more cracks in the soil. Then the grout filled the newly formed cracks. As a result, the grout content rose, thus increasing its strength. Due to erosion splitting, more soil particles separated and cemented with each other under the action of grout, forming a large number of cluster structures, as well as some large pores between the cluster structures, which was also confirmed by the microbimodal structure of pore size distribution. Due to complete splitting, the particles and grout were fully mixed and arranged more closely, so the microbimodal pore structure disappeared, and the strength rose more obviously. Therefore, a similar effect to jet grouting was produced in the consolidated body, which also explains the grout diffusion characteristics at $0.4 \mathrm{MPa}$ in Figure 5. Meanwhile, it was found that seepage always occurred in the remaining 3 types. As proven in Figure 9, the soil body in the mold remained intact after splitting, precisely because of the seepage diffusion after splitting. In previous studies, the type of seepage and erosion was generally considered as permeation diffusion in a broad sense, but it can still be classified using this theory. For example, the permeation in the gravel is the seepage type in $[29,30]$, the seepage erosion type in [31], and the erosion splitting type in $[32,33]$. The splitting process of foaming polyurethane in the soil body and its splitting pattern are shown in Figure 16, also belonging to the erosion splitting type. However, because of its rapid reaction and easy expansion properties, its permeation process during the splitting is not obvious [26]. Cement soil mixing piles [5] and high-pressure jet grouting can be defined as complete splitting type.

\section{Engineering Application}

A dike building is located in the southeast of a county in Jiangxi Province, with an elevation of 21.33-23.28 m, a width of $5.5 \mathrm{~m}$, and an upstream slope ratio of $1: 2.5-1: 3.0$. The stratigraphic distribution from top to bottom includes $7.3 \mathrm{~m}$ of Q4 plain fill, $3.9 \mathrm{~m}$ of Qa14 silty soil, and $3.9 \mathrm{~m}$ of silty clay. Owing to the incomplete compaction and poor construction quality, part of the dike body suffers from serious seepage and leakage. In order to prevent severer seepage failure at the dike, prompt treatment is needed. Therefore, the dike was first detected using the high-density electrical method to determine the location of leakage caused by the noncompaction of soil body. Then the dike was reinforced by 


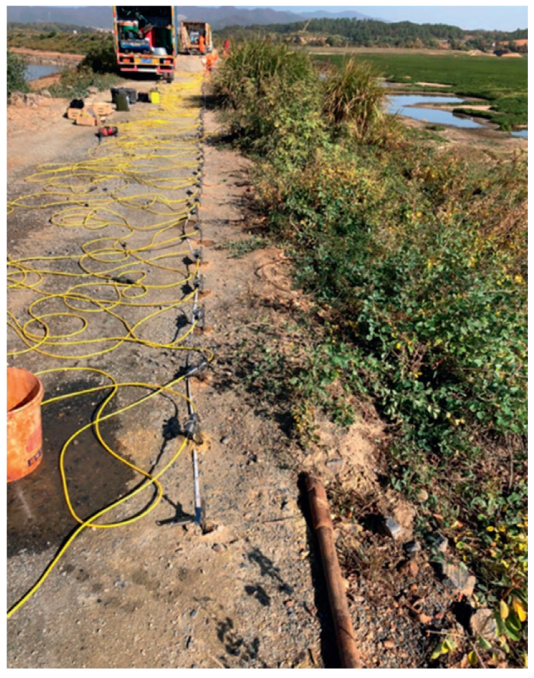

FIGURE 17: High density electrical detection.

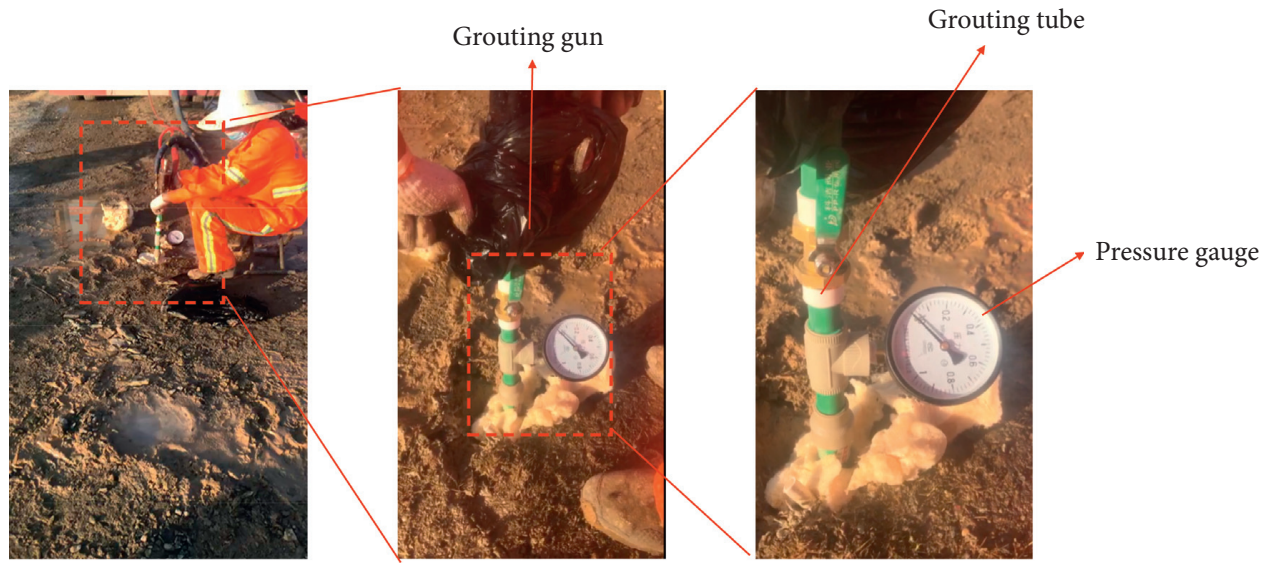

FIgURE 18: In situ grouting.

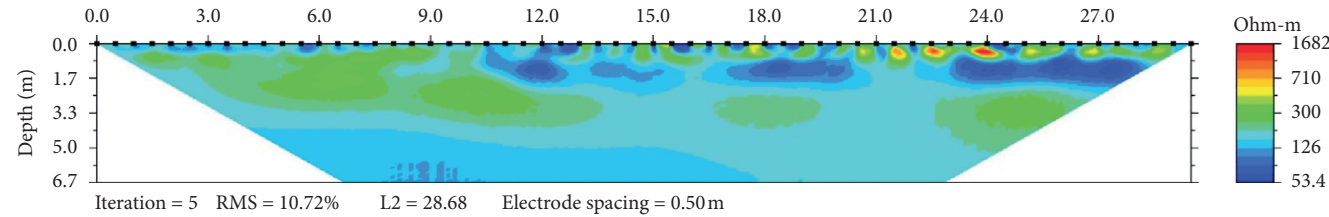

(a)

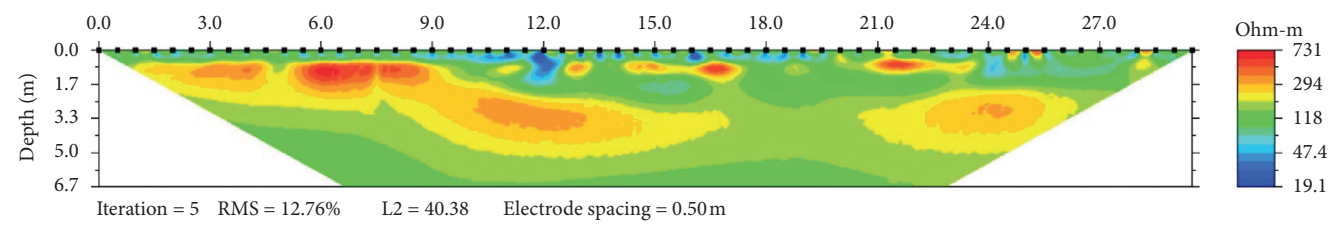

(b)

Figure 19: High-density electrical detection results. (a) Before grouting. (b) After grouting.

permeation grouting with polyurethane. Finally, the dike was retested by high-density electrical method to evaluate the grouting repair effect. The specific implementation process and results are as follows: 
(1) Detection: SuperSting R8 high-density electrical detection technique (AGI) was used to arrange the measuring line at the upstream face to determine the location of leakage. The measuring line was $30 \mathrm{~m}$ long, the electrode spacing was $0.5 \mathrm{~m}$, and the number of electrodes was 60 . The dipole-dipole detection was adopted, and the high-density electrical detection process is shown in Figure 17.

(2) Grouting: Permeable polyurethane grouting material was used for impermeable reinforcement of the dike. Grouting holes were arranged at an interval of $1 \mathrm{~m}$ along the longitudinal axis of the dike. The diameter of the grouting holes was $5 \mathrm{~cm}$, the depth of the holes was $7 \mathrm{~m}$, the grouting pressure was $0.2 \mathrm{MPa}$, and the grouting tube was $6.5 \mathrm{~m}$ long. The on-site grouting is shown in Figure 18.

(3) Evaluation of grouting effect: The high-density electrical method was used to retest the repair area to evaluate the impermeable reinforcement effect.

The results of high-density electrical detection (Figure 19) showed that the overall resistivity of the dike significantly rose after grouting, and the resistivity was as low as $60-120 \Omega \cdot \mathrm{m}$ before grouting. After repair by permeation grouting, the overall resistivity of the dike reached about $300 \Omega \cdot \mathrm{m}$. At the suspected area of hidden danger, the resistivity reached about $400 \Omega \cdot \mathrm{m}$. Therefore, it can be seen that the grouting reinforcement effect is desirable, and the permeable polymer successfully permeates into the pores of the soil body under the grouting pressure and then cements the soil body, so as to improve the impermeability and stability of the dike. In the grouting process, the pressure gauge value was always $0 \mathrm{MPa}$, indicating that the soil body is not dense, and, on the other hand, the polyurethane diffusion effect is better.

\section{Conclusions}

In this paper, a nonfoaming permeable polyurethane grouting material was developed, the diffusion law in the silt was studied through lab grouting test, and the effect of grouting on the mechanical properties of soil body was explored using unconfined compressive strength test. The mechanism of action of polymer grouting on the soil body was analyzed via SEM-EDS and mercury intrusion test, followed by engineering application. The main conclusions are as follows:

(1) With the increase of grouting pressure, the macrodiffusion mode of polyurethane in the soil body is changed from permeation diffusion to splittingpermeation diffusion. Splitting diffusion is the result of accumulation of microcracks in the soil body to a certain extent under pressure, after which the grouting pressure has little effect on the diffusion rate.

(2) Polyurethane can significantly enhance the strength of the soil body, and the higher the grouting pressure, the more obvious the strength enhancement. The main reason is that the increase in grouting pressure will cause more microcracks in the soil body, and then more grout is injected into local soil body, thus increasing the strength more significantly.

(3) The results of SEM and MIP showed that the porosity of the consolidated body was greatly reduced after grouting. The EDS results showed that the unconfined compressive strength had a strong correlation with the percentage of element $C$, suggesting that the polyurethane adheres to and permeates into the surface of the soil particles to enable them to cement with each other. Therefore, it is believed that the polyurethane strengthens the soil body mainly through wrapping, complexing, and filling.

(4) Microscopically, the mechanism of grouting on the soil body is classified into 4 types: seepage, erosion, erosion splitting, and complete splitting, and seepage occurs in the remaining 3 types simultaneously. The test results also proved that the effect of the grout on the soil body changed from permeation to erosion splitting through changing the grouting pressure. However, when the grouting pressure exceeded a certain value, complete splitting would occur. At this time, the particles and grout were mixed and arranged more closely, the microbimodal pore structure disappeared, a similar effect like jet grouting was produced, and the strength was enhanced more obviously. For example, the strength of the consolidated body reached $4.34 \mathrm{MPa}$ under the grouting pressure of $0.4 \mathrm{MPa}$.

(5) It was proven in engineering practice that the impermeable reinforcement effect of polyurethane is desirable, and the resistivity of the soil body is greatly improved after grouting.

\section{Data Availability}

The data used to support the findings of this study are available from the corresponding author upon request.

\section{Conflicts of Interest}

The authors declare that they have no conflicts of interest.

\section{Acknowledgments}

This work was supported by the National Key R\&D Program of China (no. 2017YFC1502606) and the National Natural Science Foundation of China (NSFC) (no. 51679219).

\section{References}

[1] S. David Alós, K. Engin, and D. Frank, "Plastic concrete for cut-off walls a review," Construction and Building Materials, p. 255, Article ID 119248.

[2] U.S. Bureau of Reclamation, Design Standards No. 13: Embankment Dam, Cutoff Walls, Revision, Washington, DC, USA, 2014. 
[3] H. Abbaslou, A. R. Ghanizadeh, and A. T. Amlashi, "The compatibility of bentonite/sepiolite plastic concrete cut-off wall material," Construction and Building Materials, vol. 124, no. 15, pp. 1165-1173, 2016.

[4] J. Wu, Y. Deng, X. Zheng et al., "Hydraulic conductivity and strength of foamed cement-stabilized marine clay," Construction and Building Materials, vol. 222, pp. 688-698, 2019.

[5] H. Bayesteh and M. Sabermahani, "Field study on performance of jet grouting in low water content clay," Engineering Geology, vol. 264, Article ID 105314, 2019.

[6] S. Li, F. Sha, R. Liu, Q. Zhang, and Z. Li, "Investigation on fundamental properties of microfine cement and cement-slag grouts," Construction and Building Materials, vol. 153, no. 30, pp. 965-974, 2017.

[7] F. Sha, S. Li, R. Liu, Z. Li, and Q. Zhang, "Experimental study on performance of cement-based grouts admixed with fly ash, bentonite, superplasticizer and water glass," Construction and Building Materials, vol. 161, pp. 282-291, 2018.

[8] N. Viet-Hung, R. Sébastien, and G. Jean-Louis, "Influence of cement grouts composition on the rheological behaviour," Cement \& Concrete Research, vol. 41, no. 3, pp. 292-300, 2011.

[9] Y.-h. Liu, P. Yang, T. Ku, and S.-w. Gao, "Effect of different nanoparticles on the grouting performance of cement-based grouts in dynamic water condition," Construction and Building Materials, vol. 248, Article ID 118663, 2020.

[10] A. Cinar and N. Maerz, "An Experimental Study of Chemical Grouting Materials for Optimum Mechanical Performance [C]//Geo-Congress 2020," Foundations, Soil Improvement, and Erosion, pp. 716-726, American Society of Civil Engineers, Reston, VA, 2020.

[11] Z. Zhou, X. Du, S. Wang, and H. Zang, "Analysis and engineering application investigation of multiple-hole grouting injections into porous media considering filtration effects," Construction and Building Materials, vol. 186, no. 20, pp. 871-883, 2018.

[12] Z. Zilong, D. Xueming, W. Shanyong, C. Xin, and C. Lu, "Micromechanism of the diffusion of cement-based grouts in porous media under two hydraulic operating conditions: constant flow rate and constant pressure," Acta Geotechnica, vol. 14, no. 3, pp. 825-841, 2018.

[13] O. Chupin, N. Saiyouri, and P.-Y. Hicher, "The effects of filtration on the injection of cement-based grouts in sand columns," Transport in Porous Media, vol. 72, no. 2, pp. 227-240, 2008.

[14] A. Pandey and A. Rabbani, "Soil stabilisation using cement," International Journal of Civil Engineering and Technology, vol. 8, no. 6, pp. 316-322, 2017.

[15] F. Pakir, A. Marto, N. Z. Mohd Yunus et al., "Effect OF sodium silicate as liquid based stabilizer ON shear strength OF marine clay," Jurnal Teknologi, vol. 76, no. 2, 2015.

[16] M. R. Golhashem and E. Uygar, "Volume change and compressive strength of an alluvial soil stabilized with butyl acrylate and styrene," Construction and Building Materials, vol. 255, Article ID 119352, 2020.

[17] S. Kazemian, B. B. K. Huat, P. Arun et al., "A review of stabilization of soft soils by injection of chemical grouting," Australian Journal of Basic and Applied Sciences, vol. 4, no. 12, pp. 5862-5868, 2010.

[18] A. K. Bhardwaj, R. A. Mclaughlin, and G. J. Levy, "Depositional seals in polyacrylamide-amended soils of varying clay mineralogy and texture," Journal of Soils and Sediments, vol. 10, no. 3, pp. 494-504, 2010.
[19] M. D. Bishop, S. Kim, A. M. Palomino, and J.-S. Lee, "Deformation of "tunable" clay-polymer composites," Applied Clay Science, vol. 101, pp. 265-271, 2014.

[20] J. Peng, H. Ye, and A. N. Alshawabkeh, "Soil improvement by electroosmotic grouting of saline solutions with vacuum drainage at the cathode," Applied Clay Science, vol. 114, pp. 53-60, 2015.

[21] J. Chu, V. Ivanov, M. Naeimi, V. Stabnikov, and H.-L. Liu, "Optimization of calcium-based bioclogging and biocementation of sand," Acta Geotechnica, vol. 9, no. 2, pp. 277-285, 2014.

[22] M. Y. Fattah, M. M. Al-Ani, and M. T. A. Al-Lamy, "Wetting and drying collapse behaviour of collapsible gypseous soils treated by grouting," Arabian Journal of Geosciences, vol. 8, no. 4, pp. 2035-2049, 2015.

[23] S. Saleh, N. Z. M. Yunus, K. Ahmad, and N. Ali, "Improving the strength of weak soil using polyurethane grouts: a review," Construction and Building Materials, vol. 202, no. 30, pp. 738-752, 2019.

[24] P. K. R. Vennapusa, Y. Zhang, and D. J. White, "Comparison of pavement slab stabilization using cementitious grout and injected polyurethane foam," Journal of Performance of Constructed Facilities, vol. 30, no. 6, Article ID 04016056, 2016.

[25] C. Cui, C. Guo, and F. Wang, "Fatigue analysis for void repair of cement concrete pavement with under slab by polymer grouting," Civil Engineering Journal, vol. 5, no. 7, pp. 1452-1464, 2019.

[26] C. Guo, B. Sun, D. Hu, F. Wang, M. Shi, and X. Li, "A field experimental study on the diffusion behavior of expanding polymer grouting material in soil," Soil Mechanics and Foundation Engineering, vol. 56, no. 3, pp. 171-177, 2019.

[27] S. Li, R. Liu, Q. Zhang, and X. Zhang, "Protection against water or mud inrush in tunnels by grouting: a review," Journal of Rock Mechanics and Geotechnical Engineering, vol. 8, no. 5, pp. 753-766, 2016.

[28] S. Çelik, "An experimental investigation of utilizing waste red mud in soil grouting," KSCE Journal of Civil Engineering, vol. 21, no. 4, pp. 1191-1200, 2017.

[29] F. Jorne, F. M. A. Henriques, and L. G. Baltazar, "Evaluation of consolidation of grout injection with ultrasonic tomography," Construction and Building Materials, vol. 66, no. 15, pp. 494-506, 2014.

[30] F. Jorne, F. M. A. Henriques, and L. G. Baltazar, "Evaluation of consolidation of different porous media with hydraulic lime grout injection," Journal of Cultural Heritage, vol. 16, no. 4, pp. 438-451, 2014.

[31] M. Y. Fattah, M. M. Al-Ani, and M. T. A. Al-Lamy, "Studying collapse potential of gypseous soil treated by grouting," Soils and Foundations, vol. 54, no. 3, pp. 396-404, 2014.

[32] Z. M. Zhang, J. Zou, J. Y. He et al., "Laboratory tests on compaction grouting and fracture grouting of clay," Chinese Journal of Geotechnical Engineering, vol. 31, no. 12, pp. 1818-1824, 2009.

[33] P. Li, Q. S. Zhang, S. C. Li, and X. Zhang, "Time-dependent empirical model for fracture propagation in soil grouting," Tunnelling and Underground Space Technology, vol. 94, Article ID 103130, 2019. 